Rhode Island College

Digital Commons @ RIC

\title{
Barriers to Nurses Reporting Workplace Violence in the Emergency Department
}

Christine M. Pierce

Rhode Island College

Follow this and additional works at: https://digitalcommons.ric.edu/etd

Part of the Nursing Commons

\section{Recommended Citation}

Pierce, Christine M., "Barriers to Nurses Reporting Workplace Violence in the Emergency Department" (2015). Master's Theses, Dissertations, Graduate Research and Major Papers Overview. 123.

https://digitalcommons.ric.edu/etd/123

This Major Paper is brought to you for free and open access by the Master's Theses, Dissertations, Graduate Research and Major Papers at Digital Commons @ RIC. It has been accepted for inclusion in Master's Theses, Dissertations, Graduate Research and Major Papers Overview by an authorized administrator of Digital Commons @ RIC. For more information, please contact digitalcommons@ric.edu. 


\title{
BARRIERS TO NURSES' REPORTING WORKPLACE VIOLENCE IN THE EMERGENCY DEPARTMENT
}

\author{
by \\ Christine M Pierce BSN, RN
}

\author{
A Major Paper Submitted in Partial Fulfillment \\ of the \\ Master of Science in Nursing \\ School of Nursing \\ Rhode Island College \\ 2015
}




\begin{abstract}
Violence in healthcare is a global problem and nurses are subjected to workplace violence (WPV) more than any healthcare professional. The International Council of Nurses (ICN) reports that nurses are three more likely to experience workplace violence than any other group. The Emergency department $(\mathrm{ED})$ is one of the most frequent locations where this occurs. There is evidence that this problem is severely underestimated due to the under-reporting of WPV events and as such negative consequences of WPV impact patient outcomes. Additional evidence suggests that the percentage of individuals reporting such events is low. The purpose of this study was to explore nurses' experiences of WPV, whether events of WPV were being reported and if not what were the barriers that contributed to the events not being reported. This mixed method study utilized a 19 item checklist of WPV behaviors which was adapted from a 2007 Emergency Nurses Association (ENA) study (ENA Workplace Violence Toolkit, 2010). A total of 54 nurses from a local ED were surveyed. The Theory of Planned Behavior was used to guide this project. Results of the study suggested that while a majority of nurses experienced WPV, there was a dramatic culture of under-reporting. A majority of participants indicated reporting would not result in changes and therefore not worth reporting. This study suggests evidence of WPV as a flourishing problem and that documenting the extent of WPV events continues to be problematic due to underreporting. Future research needs to further explore barriers to reporting WPV and develop policies and protocols to increase reporting of WPV and ultimately mitigate WPV.
\end{abstract}




\section{Acknowledgements}

I would first like to deeply thank one of my best friends, Sherrye Durante, who got me started on this challenging journey four years ago. Obtaining a Master's Degree and becoming a nurse practitioner had been a lifelong dream that I never quite managed to begin for many different reasons. Sherrye refused to take no for an answer and literally dragged me into research class with her, and so it began. She encouraged me, supported me, instilled great confidence in me, and never doubted me for a second.

This project is the culmination of $3 \frac{1}{2}$ years of hard work and determination. There were many challenges I faced along the way educationally and personally, including health problems. With the support of my family and friends, especially my daughter Katie, my son Nick (via telephone), and my boyfriend Rik, I have achieved my goal! Their patience and understanding truly helped me to try to balance work, school, research projects, and personal time.

I wish to thank Claire Creamer, my advisor and first reader, for her help and encouragement with this challenging project. In addition, I would like thank Cynthia Padula, my P.I. and second reader, and Linda Dykstra, my third reader.

This journey has been challenging, amazing, difficult, stressful, and life-changing. I would not change a thing! I have met so many new people and made so many new and wonderful friends. My graduating class includes some of the most intelligent and kindest people I have ever known. Two very special friends, Veronica Seippel and Christina Dickson, took me under their wing, and together we made it through this with flying colors. They were my study 
buddies, friends, organizers, and technical advisors. I know we will always stay friends and perhaps we will be colleagues together one day!

A special note to my mom, Shirley McCormick, who passed away 4 years ago; you were an extraordinary mother, nurse, and scholar. I thank you for my passion for nursing and for the "brains" to accomplish my dreams; I know you would be very proud of me. 
Table of Contents

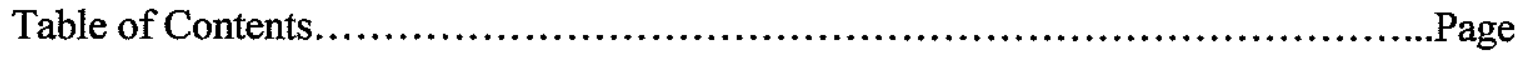

Background and Statement of the Problem..........................................

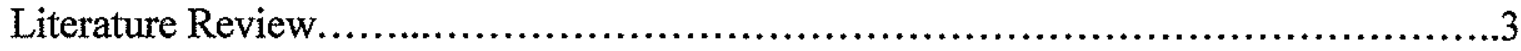

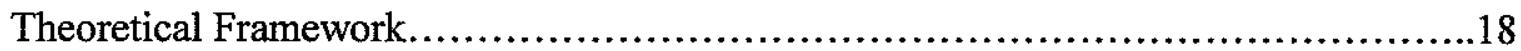

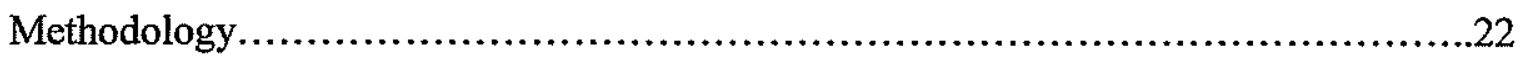

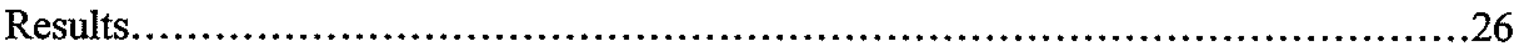

Summary and Conclusions................................................... 37

Recommendations and Implications...............................................4

References...................................................................45

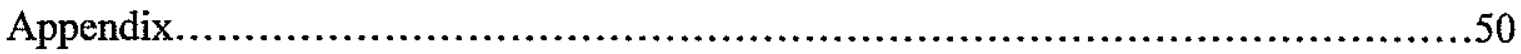


Barriers to Nurses' Reporting Workplace Violence In the Emergency Department

\section{Background and Problem Statement}

Workplace violence (WPV) occurs in many forms including physical assault, emotional or verbal abuse, and threatening, harassing or coercive behavior. There are a multitude of definitions of workplace violence and this ambiguity contributes to the dilemma of recognizing, evaluating, and preventing the increasing incidence of violence in the workplace. The National Institute of Occupational Safety and Health (NIOSH) defined workplace violence as "violent acts (including physical assaults and threats of assaults) directed towards persons at work or on duty" (NIOSH, 2002, p.1)

Violence in the workplace is an escalating problem for healthcare professionals in all settings. Nurses are subject to one of the highest rates of documented WPV (Campbell et al., 2011). The International Council of Nurses (ICN) reported that nurses are three times more likely to experience violence than any other professional group (Keely, 2002). In 2009, Gacki-Smith et al. conducted a study in which nurses who belonged to The Emergency Nurses Association (ENA) were surveyed to investigate the nurses' experience, attitude, and perceptions regarding violence in the emergency department (ED). This study showed that violence is highly prevalent against ED nurses and nurses consider this a very serious issue. Approximately $25 \%$ of the respondents reported experiencing physical assault over 20 times in a two year period and verbal abuse over 200 times (Gacki-Smith et al., 2009). 
Despite these alarming statistics, there is evidence that violence is under

reported. Respondents expressed fear of retaliation, lack of support, and issues with administration as barriers to reporting WPV. Results in the Gacki-Smith et al. (2009) study revealed that nurses who felt there were no barriers to reporting were less likely to have experienced frequent physical violence.

Violent acts can have a profound effect on nurses' physical safety, emotional well-being, job satisfaction, and can negatively impact patient care. It is essential that accurate reporting and documentation of WPV is supported and encouraged. Identifying consistent and important reasons for under reporting could prove instrumental to developing programs and policies to reduce the incidence of violence in the ED. The purpose of the study is to explore if nurses are under reporting violent events in the emergency department and what factors are contributing to this behavior.

Next, the review of the literature will be presented. 


\section{Literature Review}

PubMed, CINAHL, and OVID databases were utilized to search for articles using keywords 'workplace violence', 'emergency room', 'violence against nurses', 'barriers to reporting workplace violence', and 'violence in healthcare'. The search included articles published since 2000 to the present. Initial results, as well as the bibliographic reference lists for many of these published articles, were utilized to expand the resources. The search revealed an extensive amount of literature regarding workplace violence with many prevalent themes.

\section{Workplace Violence Definition}

The definition of workplace violence varies greatly and is dependent on the occupation, setting, and origin of the report or statement that is being issued. Violence in the workplace is also referred to as workplace violence (WPV). In 2002, a joint program initiated by the International Labor Office (ILO), the International Council of Nurses (ICN), the World Health Organization (WHO), and the Public Services International (PSI) was launched to develop policies and practices to address the issue of WPV internationally. A synthesis report of this initiative, authored by DiMartino in 2002, defined WPV as incidents where staff are assaulted, abused, or threatened in any circumstances in which work is involved. Included was physical as well as psychological harm, bullying, and harassment. The scope of behaviors consistent with WPV is 
considered wide and ranges from offensive language to homicide (Lundrigan, Hutchings, Matthews, Lynch, \& Goosney, 2010; McPhaul \& Lipscomb, 2004; Speroni, Fitch, Dawson, Dugan \& Atherton, 2014). The National Institute of Occupational Safety and Health (2002) defined workplace violence as "violent acts (including physical assaults and threats of assaults) directed toward persons at work or on duty" (NIOSH, 2002 , p.1). Workplace violence can be generally described as emotional, physical, verbal abuse, or threatening and coercive actions in the work setting that causes harm (GackiSmith et al., 2009; McPhaul \& Lipscomb, 2004; Anderson, 2002).

Physical assault is described as including such behaviors as hitting, punching, and biting. All types of assault, whether intentional or dementia-related, should be considered as violence (Danesh, Malvey, \& Fottler, 2008). Aggressive acts and language that are intended to create fear and apprehension are also considered violence (Keely, 2002). Behaviors like these can cause psychological damage and contribute to stress, burnout, and job dissatisfaction. The Occupational Safety and Health Administration defined workplace violence as the act of violence or the threat of violence against employees (Occupational Safety and Health Administration, 2012). This can occur in or outside of the workplace and can range from threats and verbal abuse to assaults or even homicide. Approximately two million American workers are victims of WPV every year. Some workers are at increased risk; included in this group are healthcare workers and social service workers (NIOSH, 2002). The Canadian Centre for Occupational Health and 
Safety defined WPV as any act in which a person is intimidated, abused, threatened, or assaulted while at work or outside of work. Types of behaviors include threatening phone calls, rumors, swearing, harassment, physical abuse, and intimidation (Canadian Centre for Occupational Health and Safety, 2012).

The ENA has sponsored several studies on WPV and proposed a definition of WPV as an act of "aggression directed towards persons at work or on duty and ranges from offensive or threatening language to homicide. WPV is commonly understood as any physical assault, emotion or verbal abuse or threatening, harassing or coercive behavior in the work setting that causes physical or emotional harm" (Emergency Nurse Association, 2010). The United States Department of Labor's Occupational Safety and Health Administration defines WPV as "an action (verbal, written, or physical aggression), which is intended to control or cause, or is capable of causing, death or serious bodily injury to oneself or others, or damage to property. Workplace violence includes abusive behavior toward authority, intimidating or harassing behavior, or threats" (OSHA, 2012, p. 1)

The University Of Iowa's Injury Prevention Center (UIIPC) conducted a research workshop in 2001 with the goal of developing strategies to reduce WPV. In an effort to better understand the causality and ultimately develop preventative solutions the UIIPC divided WPV into four categories: 
Criminal Type: (Type I). The perpetrator has no relationship to employees and this is usually committed during a crime;

Customer/Client Type: (Type II) the perpetrator has a legitimate relationship with the business, customers, clients, students, etc. A large proportion of these type incidents occur in the healthcare industry;

Worker-on-Worker: (Type III) the perpetrator is an employee or past employee of the business;

Personal Relationship: (Type IV) the perpetrator has a personal relationship with the intended victim (Merchant \& Lundell, 2001).

Although all healthcare workers can be subject to all four types of violence, the focus of this work will be Type II violence using the definition as proposed by NIOSH. Workplace Violence in Healthcare

Violence seems to be so common in the workplace, especially in the healthcare sector, that it may be considered as 'part of the job'. While ambulance/EMS workers are considered at the highest risk, nurses are three times more likely to suffer WPV (DiMartino, 2002). The majority of the nursing workforce is female and this highlights a gender-based dimension to this problem as well (DiMartino, 2002).

The ICN in 2006 published a position paper regarding abuse and violence against nursing personnel. Their statement acknowledged that acts of abuse and violence against any person should be condemned, but highlighted the particular high risk of nursing 
personnel. They purport that amongst healthcare personnel, nursing is the most vulnerable and at the highest risk for WPV. The report further emphasized that verbal abuse should not be minimized and that the effects of the violence can extend to third parties, families and observers (International Council of Nurses, 2006).

In a commentary paper about the epidemic of violence and abuse in Western Australia, Chapman and Styles (2006) discussed the need for future research to address the violence and aggression suffered by nurses working in the healthcare system. They acknowledged an increase in violent incidents involving nurses in Australia as well as worldwide, and the ineffective initiatives in place to mitigate these occurrences.

Violence in the workplace poses a significant occupational risk, especially in service facilities and hospitals. Workplace violence is pervasive and should be a grave concern to all healthcare members including staff and management (Hader, 2008). Workplace violence is one of the dangerous and complex occupational hazards that nurses currently face. Recent.data indicates that healthcare workers and social services experience WPV at a rate of 10.7 per 10,000 full time workers as compared to 2 per 10,000 for other industries (Greene, 2009). Violence perpetrated by clients or patients can happen in any healthcare setting but is more prevalent in mental-health psychiatric settings, geriatric units, and emergency departments. Healthcare workers of any kind can be the targets but nursing and unlicensed direct care staff is at the highest risk (Greene, 2009). The Bureau of Labor Statistics (BLS) reported a 13\% increase in assaults to 
healthcare and social assistive personnel for the period 2009 to 2010 (OSHA, 2012). A 2008 survey by Nursing Management found that over $80 \%$ of nurse leaders experienced violence in some form in their work setting (Hader, 2008). Despite these statistics, there are few healthcare organizations that have comprehensive workplace safety programs.

Campbell et al. (2011) examined prevalence and risk factors for WPV by utilizing data from a cross-sectional survey. A total of 2166 nursing personnel, including nurses and other nursing personnel, LPNs, and patient care technicians, from metropolitan health care institutions in the U.S. responded to this survey. Almost one third (30\%) of nursing personnel reported experiencing WPV in a 12 month period. The violence was reported as physical or psychological in approximately equal percentages. Nurses reported overall greater rates of WPV than non-nurses in every clinical area. Respondents who reported physical violence cited the patient as the perpetrator in over $90 \%$ of the cases, as compared to $54 \%$ when psychological violence was reported. Co-workers, physicians, and supervisors were also reported as perpetrators. The strongest risk factors for physical WPV were identified as working in psychiatric units or EDs. Working on these units also revealed a potential increased risk for psychological violence but findings were not significant. These findings were consistent with other large studies conducted at similar medical institutions. Possible explanations for these similarities in higher risk include patient characteristics, environmental conditions, and staff characteristics.

\section{Workplace Violence in the Emergency Department}


Workplace violence has become increasingly commonplace in the US and particularly in the healthcare setting. Among all healthcare settings, the ED has been identified as especially high risk. Workers in the ED also face a greater risk of physical assault as compared to other settings. Workplace violence is a significant problem that can compromise health and safety of all employees, self- esteem, work performance, and job satisfaction. Violence against ED healthcare workers is a serious problem with grave implications to the victims, patients, and the hospitals (Crilly, Chaboyers, \& Creedy, 2004; Gacki-Smith et al., 2009; Gates, Ross, \& McQueen, 2006; Kowalenko et al., 2012).

Keely (2002) published an article regarding the recognition and prevention of hospital violence. Keely reported violence as the second leading cause of death in the workplace, with nurses working in critical care areas and EDs as being particularly vulnerable. Physical confrontations and verbal abuse in the ED is well documented. According to Keely, recognizing the potential for violence to occur and identifying potentially violent patients can help to mitigate violent events. Detecting these potentially violent situations can provide an opportunity for therapeutic interventions. Emergency rooms are identified as an area of practice at high risk for assault and violence (Catlette, 2005).

A descriptive qualitative study by Catlette (2005) sought to explore the issue of WPV. Eight nurses who worked in a level 1-trauma center participated in face-to-face interviews. The interviews explored the phenomenon of workplace violence from the 
perspective of emergency nurses who had experienced violence while on duty. An interview guide consisting of seven questions associated with a pilot study previously conducted was the format used for the interviews. Some of the interview questions included the nurses' perspectives on why they chose emergency nursing, how safe they felt at work, specific violent occurrences, and how they felt their education program prepared them to deal with aggression and violence. The interviews were conducted in private areas when the nurses were not on duty. The author identified two themes that were recurrent. The first identified theme related to inadequate safety measures present in the EDs and the second theme related to vulnerability. The nurses who worked in this environment discussed the absence and inadequacy of specific safety measures. Participants spoke to the concerns that safety barriers such as metal detectors, secured doors, policies regarding police/security personnel, and lack of employee training on management of a potentially volatile or violent occurrence were lacking. The nurses expressed another recurring theme of vulnerability. In this study, vulnerability related to the perspective of not feeling safe at work due to the potential presence of weapons being brought into the ED and due to the unpredictability of psychiatric patients as well as patients who may be under the influence of drugs and alcohol. The nurses believed that the inadequate safety measures contributed to their vulnerability to violence. Providing education and appropriate resources was described as a major prevention strategy that can be utilized to help identify risks and minimize the negative consequences of WPV. 
The Emergency Nurse Association (ENA), in response to members' concern with escalating violence, sponsored a quantitative study which attempted to explore nurses' perceptions and experiences with WPV (Gacki-Smith et al., 2009). The study was the first national study of emergency nurses regarding WPV. In the study the authors described workplace violence as any physical, verbal, emotional, or coercive behavior that causes mental or physical harm. The purpose of the study was to investigate nurses' experiences of WPV as well as to explore the nurses' perceptions of what constituted WPV. The authors sought to identify what were the perceived contributing factors to violence, incidences of violence, and the nurses' reporting behaviors. The 69-item survey tool was made available to all ENA members currently working in US EDs for a onemonth period during 2007. A total of 3,465 emergency nurses responded, which was $10.9 \%$ of the total ENA membership. Results indicated that $23 \%(n=811)$ of the respondents had reported frequent physical violence experience (FPVE). Sixty seven percent $(n=2321)$ of the respondents perceived their safety at or below 5 on a 10-point scale (where $1=$ not at all safe and $10=$ extremely safe). Findings suggested that WPV might be under reported due to the lack of a uniform definition of WPV (Gacki-Smith et al., 2009). Additional findings included the perception that WPV is an unavoidable part of the job and the nurses do not feel safe in their workplaces. Over $50 \%$ reported being spit on, hit, pushed/shoved, scratched, and kicked. Verbal abuses, including 
yelling/cursing, intimidation, and sexually harassing language/innuendo, were reported by over $70 \%$ of participants (Gacki-Smith et al., 2009).

In the fall of 2011, employees working at Rhode Island Hospital were emailed a Violence Risk Self-Assessment Checklist (Dykstra, 2011). The purpose of this survey was to obtain baseline data about nursing staff perceptions related to violence. This survey was prompted by a recommendation by the ENA as part of their violence reduction program. The checklist was distributed to employees of the ED including nurses, technicians, secretaries, family assistants, and unit assistants. Excluded were physicians, residents, security and nursing management as the focus of the assessment was nursing personnel. One hundred seventy-seven responses were received. The results were remarkable and consistent with the reported literature. A total of $89 \%$ of participants reported that a weapon had been confiscated from a patient; $74 \%$ reported local police being called due to a violent episode; $47 \%$ felt unsafe or at risk working in the ED. The most frequently reported types of WPV were verbal abuse, threats of physical harm, sexual innuendos and verbal intimidation. Physical abuse suffered included being spit on, scratched, kicked, having objects thrown at them, sexually assaulted, and being struck. One person even reported an attempted stabbing. This same checklist (Dykstra, 2013) was emailed again in the fall of 2013 to a sample of 304 employees of the ED with the same exclusions as previously outlined. The number of responses returned totaled 139 yielding a response rate of $46 \%$ as compared to $58 \%$ in 2011 . Overall the staff reported 
feeling less safe at work, with $55 \%$ reporting feeling unsafe or at risk while working in the ED. There was an increase in episodes where police were called form $74 \%$ in 2011 to $82 \%$ in 2013 . Although the percentage of participants experiencing or witnessing violence did not increase, it was still greater than ten episodes in a two year period which is noteworthy.

While there has been a numerous studies done regarding WPV against healthcare workers and nurses in the $\mathrm{ED}$, there is a definitive lack of qualitative studies examining the personal experiences of ED nurses who have experienced WPV. Wolfe, Delao, Perlhats (2012) conducted a qualitative study in the fall of 2012 which explored nurses' experiences of WPV. Participants were recruited from ENA membership through the ENA website. Inclusion criteria for participation were selective for nurses who had reported violence, either physical or verbal, while working in the ED. The authors were attempting to better understand the precursors of violence and the sequelae of these violent events. A total of 46 participants submitted narrative accounts of their experiences with violence in the ED. Three broad themes were identified from the data:

environmental, personal, and cue recognition. Environmental categories included topics regarding the culture of acceptance and the perception that work is an unsafe environment as well as the feeling that nobody cares. There were many descriptions of administrative and legal systems that are unable or unwilling to pursue charges against patients and/or family members. Common factors identified as antecedents to violence 
included psychiatric history and the presence of alcohol and/or drugs. Cue recognition was described as factors that were seemingly evident (intoxicated and violent patients) who presented as high risk for violent behavior but safety and preventative measure were not initiated, leaving nurses vulnerable without resources or recourse. Categories in the personal theme included lingering trauma, both physical and psychological, resulting in loss of responsibilities, hours, or even job relocation. There were also cases of participant denial on the impact of violence as well as the acceptance of violence and risk as part of the job. The authors concluded that violence while working in the ED is common and there appears to be a phenomenon of normalizing these behaviors by the healthcare and judicial systems. This normalization prevents effective intervention.

\section{Barriers to Reporting Workplace Violence}

Under reporting violence was a prevalent theme in the literature (Chapman \& Styles, 2006; Crilly et al., 2004; Ferns \& Diphe, 2005; Gacki-Smith et al., 2009; Keely, 2002; Kowalenko et al., 2012; Stokowski, 2010). There were many mentions of under reporting in articles and studies but minimal studies that were dedicated solely to reporting behaviors. Additionally, many institutions do not have violence reporting policies in place, which is an additional barrier (McPhaul \& Lipscomb, 2004). Nurses have the perception that violent incidents are part of the job and are expected to occur Consideration as to whether the actual intent of the patient causing harm was also found to be a factor in not reporting WPV (Crilly et al., 2004). 
The phenomenon of WPV is occurring in a covert fashion at the patient

bedside. Data on WPV is under reported or unreported (Danesh et al., 2008). Nursing staff is complacent about reporting minor injuries or assaults. The current labels used to classify different levels of violence or aggression contributes to the confusion and inconsistency of reporting. "The mismatch of classifications both minimizes and disguises the severity of patient-to-nurse workplace violence (Danesh et al., 2008, p. 362). The authors concluded that standardized terminology for violent behavior would help to unify data collection regarding this issue. Increased awareness by clinical staff and management is essential. Because WPV is often unreported, it is difficult to truly comprehend the scope of this problem (Danesh et al., 2008).

In addition to the low rates of reporting WPV experienced by nurses by patients, healthcare workers sometimes do not report acts of violence perpetrated by visitors. Reasons for not reporting include, lack of physical injury, time consuming paperwork, and the feeling that reporting would not change anything. Many of the perpetrators are patients or visitors with psychological issues, dementia, or under extreme stress and their behaviors are termed "aggressive" or "problem" and not considered violent by workers or administrators. It is essential that attention be given to improving reporting rates of WPV (Gates, Ross, \& McQueen, 2006).

A descriptive longitudinal study was conducted by Crilly et al (2003 at two public EDs in Australia. A total of 108 nurses were invited to participate and $66 \%(n=71)$ 
completed the study. The authors found that although violence was perceived as a problem, reporting of incidents was poor. Factors such as long waiting times, alcohol, drugs, and mental health issues were cited as contributing as causative elements. The authors concluded that reporting is necessary to fully comprehend the depth and extent of WPV and to identify trends and patterns. Nurses have a responsibility to document and report violent incidences to hospital administration. Documentation can also serve to alert society to the extent of this problem. Identifying trends and patterns of violence can provide a better foundation for health care planning. Effective preventative programs and safety strategies can only be developed when the scope of the problem is fully realized. In 2007, an ENA sponsored study of emergency room nurses was completed. This cross-sectional survey was conducted by Gacki-Smith et al. and consisted of a convenience sample of 3,465 ENA members. The purpose of the study was to investigate the nurses' perceptions of violence and their experiences with it. Several barriers to reporting were identified from the data. The nurses expressed the perception that reporting incidents could have a negative effect on customer service scores or reports. Administrative policies and ambiguous guidelines for documenting WPV were cited as a contributing factor. Fear of retaliation from ED management, administration, physicians, and other nursing staff were prevalent themes. Additional factors included: lack of physical injury to staff; reporting WPV was seen as a sign of weakness; lack of support from administration/management; and the attitude that violence comes with the job. 
Nurses who felt that there were no barriers to reporting WPV were less likely to have experienced frequent physical violent episodes (Gacki-Smith et al., 2009).

In summary, the literature review identified a definition of workplace violence that is commonly used in the literature. In addition, the prevalence of workplace violence against nurses, particularly in the emergency department, is highlighted and established. The existence and impact of under-reporting was also examined. The purpose of this study was to examine reasons for this under-reporting to further add to the body of knowledge regarding this phenomenon. 


\section{Theoretical Framework}

The existence and occurrence of WPV in the emergency department against healthcare workers, specifically nurses, is well documented in the literature. A consistent finding across the literature reviewed was under reporting of WPV. What is unclear is the reason for the under reporting. The Theory of Planned Behavior (TBP) was used to guide this study.

The TPB was developed in 1985 by Icek Ajzen as an extension of the Theory of Reasoned Action (TRA) which was written in collaboration with Martin Fishbein in 1980 (Ajzen, 2012). The TPB explores the relationship between beliefs, attitudes, intentions, and behavior. The theory posits that people are rational and make informed decisions. Beliefs reflect the information people have in relation to the performance of a given behavior, but this information can be inaccurate and incomplete. Nevertheless, no matter how people form their beliefs, they are consistent with their behavior based on those beliefs (Ajzen, 2011). The TPB proposes that a person's behavior is most accurately predicted by intentions. Intentions are predicted by three factors: attitudes about the behavior, subjective norms (an individual's perception about what is acceptable by others), and the individuals' beliefs regarding their control over the behavior (Cameron, Ginsburg, Westhoff, \& Mendez, 2011).

Attitude is described as a combination of feeling, beliefs, intentions, and perceptions. It represents each individual's positive or negative evaluation about 
performing a behavior. Attitude combined with knowledge can help the person analyze whether performing a behavior is a positive or negative experience (McEwen \& Wills, 2011). Attitude towards a behavior is formed and influenced by one's behavioral beliefs about the likely outcome of a behavior and if it will be favorable or unfavorable to the person (Ajzen, 1991).

The second factor contributing to a behavior is the normative belief or subjective norm that includes social acceptability and the importance of performing the behavior. Significance of such is related to the person's referent group such as spouse, family, coworkers, etc. Relative strength or weakness of the topic as it pertains to the individual as well as their personal motivation to comply help to determine the action (Ajzen, 2012). Perceived behavioral control, also referred to as control beliefs, considers how the individual perceives the factors that influence the behavior and the strength of those factors. "In general, the more favorable the attitude and subjective norm, the greater the perceived control and the stronger would be the person's intentions to perform the behavior" (McEwen \& Wills, 2011, p. 293). When people have a certain degree of control or perceived control over their behavior that are expected to follow through with their intentions.

This theory states that intentions are assumed to be causal antecedents to corresponding behaviors (Ajzen, 2012). The basic tenets of the theory are pictorially represented in Figure 1 on the following page. 


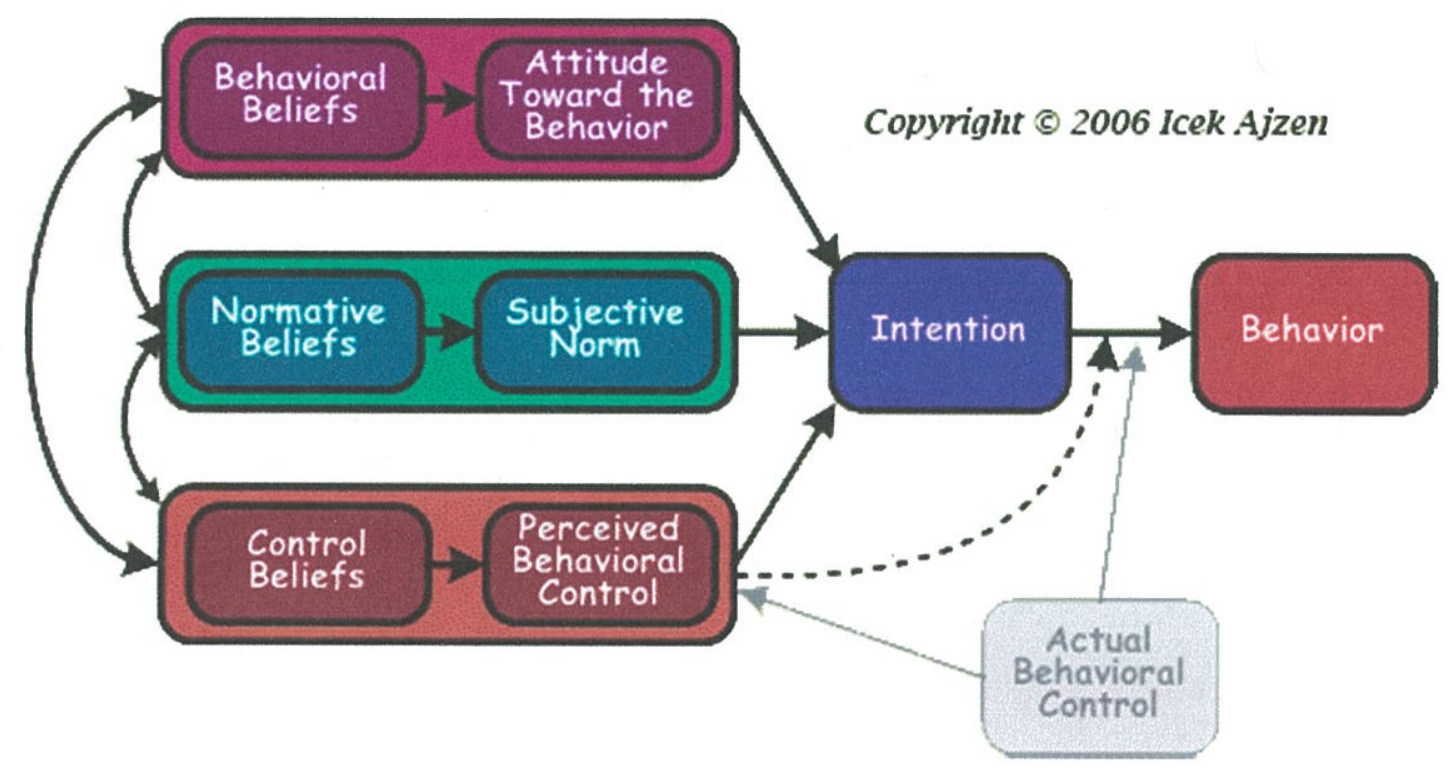

Figure 1. The Theory of Planned Behavior (Ajzen, 2006)

TPB has been utilized to predict behavior and change in behavior. The intent of this work is not to change, but to understand and analyze behavior related to under reporting of work place violence. The behavior of interest for this work is "reporting of violent events". Utilization of TPB and its concepts will frame and guide the project. Discovering the attitudes, beliefs, and experiences of nurses regarding violence can help 
to understand the reasons for under reporting and potentially serve as a future tool to

change this behavior.

Next, the methods section will be presented. 


\section{Methodology}

\section{Purpose/Research Question}

The purpose of the study was to explore if nurses are under reporting violent events in the emergency department and what factors contribute to this behavior.

The research questions for this study are what do nurses in the ED perceive as WPV behaviors and what are the perceived barriers to nurses reporting workplace violence in the emergency department.

\section{Design}

A mixed methods design utilizing a descriptive survey as well as an open-ended question was used for this study.

\section{Site}

The site for the research study was Rhode Island Hospital (RIH), which has 719 licensed beds and is an acute care teaching facility located in a metropolitan area and part of the Lifespan system. The RIH ED is the regions' only level 1 trauma center. The annual patient census for 2013 for the ED was 150,562 according to the Lifespan Annual 2013 report. The ED has 88 patient care beds.

\section{Background}

Lifespan has acknowledged that the safety of healthcare workers in the ED is at risk and has addressed it in several ways. There is a mandatory safety training program 
known as Crisis Prevention Institute (CPI) that assists staff in identifying and handling violent situations. The CPI must be completed on a yearly basis. Security personnel are present 24 hours a day with guards posted at each entrance to the ED and there is closed circuit surveillance cameras placed in strategic areas. Secretaries have panic buttons to alert security staff and have direct phone numbers to alert Providence Police of incidents. The ED is a locked unit requiring badge access to most patient care areas. Violence reporting forms are available for staff to report and document violent incidents. There is currently a program in development called Critical Incident Response Program to help staff to recognize potentially violent behavior and to communicate this quickly, consistently, and effectively to optimize safety for staff and patients.

\section{Sample}

Convenience sampling was utilized for this study. All 177 registered nurses (RN) working in the adult ED at the time data was collected, including part-time, full-time, and per-diem staff RNs, were eligible and were invited to complete the survey. Any RN who was designated as management or educational staffing was excluded from the sample. Full participation of all RN staff was the ideal goal; however a total of $30.5 \%(n=54)$ responded to the survey.

\section{Measurement}

Basic demographic data including gender, shift worked, and years of experience were requested. 
The survey tool used was a modified version of the ENA 2007 workplace

violence survey (Appendix A). Permission to use the ENA violence survey was not necessary due to the fact that the survey is in the public domain and is part of the ENA violence toolkit. The original ENA survey was evaluated for content validity and was pilot tested on a sample of 15 emergency nurses. Modifications to the original survey included omitting questions not relevant to the current research question; the wording of the questions utilized for this survey was not changed in any way from the original ENA violence survey. An additional column soliciting participants' perception of WPV behaviors was added as well as a column that sought a yes or no response as to whether a perceived event of WPV had been reported. Two open-ended questions from the original ENA survey and one additional open-ended question seeking reasons for not reporting a violent event were included.

\section{Procedures}

Verbal permission to conduct the survey was obtained from the clinical manager of RIH Emergency Department as well as the Director of the ED. The Chief Nursing Officer (CNO) was contacted and written agreement was procured. The proposal was submitted to the IRBs of both RIH and Rhode Island College and IRB approval was obtained.

An email was sent to all eligible RNs to inform them about the study in early February, 2014. The researcher also made verbal announcements during roll call at the 
start of several shifts, including all three shifts. A flyer requesting participation and describing the study was hung in the break room/roll call room one week prior to the start of the survey period and throughout the survey.

To encourage participation a raffle was offered to all nurses who filled out the survey. The prize was a $\$ 25.00$ gift certificate to the Au Bon Pain restaurant at Rhode Island Hospital. In order to maintain anonymity, each survey had a removable sticky note raffle attached, which was placed, into a separate sealed box. Once the survey was completed, the participant wrote their name on the raffle and placed into the separate sealed box.

The surveys were anonymous to ensure confidentiality and anonymity of responses. An IRB approved informational letter was included with the survey that described the purpose of the study and what participation involved. Information regarding the researcher and contact information including phone number and email was provided. Surveys were placed in the break room along with a sealed box in which to place the surveys once completed. Completion of the survey indicated consent for participation. The survey was made available for a period of three weeks after which time the researcher collected the completed surveys.

Next, the results will be presented. 


\section{Results}

The target population for this study was RNs who work in the ED at RIH. Fiftyfour nurses completed the survey, for an overall response rate of $30.3 \%$. The gender distribution for the sample included 15 males (29.4\%) and 38 females (70.3\%); one respondent did not specify gender $(1.8 \%)$. The majority of the participants $63 \%(n=34)$ had over ten years of experience in the nursing profession. Participants working days and evenings comprised $42.6 \%(n=23)$ and $44.4 \%(n=24)$ of the sample respectively; those working nights represented $12.9 \%(n=7)$ of the sample.

The survey included a 19-item checklist of 'behaviors' derived from the ENA survey (ENA workplace violence toolkit, 2010). Respondents were asked to indicate: if each behavior was considered to be violent; whether they had experienced it, and if they had reported the incident. Table 1 on the next page illustrates the participants' responses to whether the listed behaviors were considered to be violent behaviors. 
Table 1

Percentage of Participants who Considered the Listed Actions to be WPV

\begin{tabular}{|c|c|c|c|c|c|c|}
\hline \multirow{2}{*}{ Item } & \multicolumn{3}{|c|}{$\begin{array}{l}\text { Response to question } \\
\text { Total } n=54 \text { participants }\end{array}$} & \multirow{2}{*}{$\begin{array}{c}\% \\
\text { Yes }\end{array}$} & \multirow[b]{2}{*}{$\%$ No } & \multirow{2}{*}{$\begin{array}{l}\text { \% No } \\
\text { Response }\end{array}$} \\
\hline & Yes & No & $\begin{array}{c}\text { No } \\
\text { Response }\end{array}$ & & & \\
\hline Bitten & 53 & 0 & 1 & $98.1 \%$ & $\mathrm{n} / \mathrm{a}$ & $1.9 \%$ \\
\hline Called names & 51 & 3 & 0 & $94.4 \%$ & $5.6 \%$ & $0 \%$ \\
\hline Hair pulled & 47 & 7 & 0 & $87 \%$ & $13 \%$ & $0 \%$ \\
\hline $\begin{array}{l}\text { Harassed with sexual } \\
\text { language/innuendo }\end{array}$ & 53 & 1 & 0 & $98.1 \%$ & $1.9 \%$ & $0 \%$ \\
\hline Hit (e.g., punched, slapped) & 52 & 1 & 1 & $96.2 \%$ & $1.85 \%$ & $1.85 \%$ \\
\hline Hit by thrown objects & 52 & 1 & 1 & $96.2 \%$ & $1.85 \%$ & $1.85 \%$ \\
\hline Kicked & 53 & 1 & 0 & $98.1 \%$ & $1.9 \%$ & $0 \%$ \\
\hline Pinched & 49 & 5 & 0 & $90.7 \%$ & $9.3 \%$ & $0 \%$ \\
\hline Pushed/shoved & 53 & 1 & 0 & $98.1 \%$ & $1.9 \%$ & $0 \%$ \\
\hline Scratched & 50 & 4 & 0 & $92.6 \%$ & $7.4 \%$ & $0 \%$ \\
\hline Sexually assaulted & 49 & 5 & 0 & $90.7 \%$ & $9.3 \%$ & $0 \%$ \\
\hline
\end{tabular}


The majority of participants considered most behaviors to be WPV. Two

violent incidents, being threatened with physical harm and being spit on were considered violence by $100 \%(n=54)$ of the sample. Interestingly, $96.3 \%(n=52)$ considered verbal intimidation and yelling to be workplace violence. In contrast, five respondents $(9.3 \%)$ did not consider sexual assault a violent behavior, yet $98.1 \%(n=53)$ considered being harassed with sexual language/innuendo to be workplace violence. Five nurses $(9.4 \%)$ did not consider being shot at a violent behavior. Overall, all behaviors were considered by $89 \%$ or greater of participants to be indicative of violence.

Table 2 on the next page illustrates participants' responses as to whether they had personally experienced these listed behaviors 
Table 2

Percentage of Participants who Experienced the Listed Action

\begin{tabular}{|c|c|c|c|c|c|c|}
\hline \multirow{3}{*}{ Item } & \multirow{2}{*}{\multicolumn{3}{|c|}{$\begin{array}{l}\text { Response to question } \\
\text { Total } n=54 \text { participants }\end{array}$}} & \multirow{3}{*}{$\%$ Yes } & \multirow{3}{*}{$\%$ No } & \multirow{3}{*}{$\begin{array}{l}\% \text { No } \\
\text { Response }\end{array}$} \\
\hline & & & & & & \\
\hline & Yes & No & $\begin{array}{c}\text { No } \\
\text { Response }\end{array}$ & & & \\
\hline Bitten & 15 & 37 & 1 & $27.7 \%$ & $6850.0 \%$ & $1.9 \%$ \\
\hline Called names & 54 & 0 & 0 & $100.0 \%$ & $0.0 \%$ & $0.0 \%$ \\
\hline Hair pulled & 11 & 42 & 1 & $20.7 \%$ & $79.2 \%$ & $1.9 \%$ \\
\hline $\begin{array}{l}\text { Harassed with sexual } \\
\text { language/innuendo }\end{array}$ & 38 & 16 & 0 & $70.3 \%$ & $29.6 \%$ & $0.0 \%$ \\
\hline $\begin{array}{l}\text { Hit (e.g., punched, } \\
\text { slapped) }\end{array}$ & 41 & 13 & 0 & $75.9 \%$ & $24.0 \%$ & $0.0 \%$ \\
\hline Hit by thrown objects & 52 & 1 & 0 & $96.2 \%$ & $1.8 \%$ & $0.0 \%$ \\
\hline Kicked & 31 & 23 & 0 & $57.4 \%$ & $42.6 \%$ & $0.0 \%$ \\
\hline Pinched & 35 & 19 & 0 & $64.8 \%$ & $35.2 \%$ & $0.0 \%$ \\
\hline Pushed/shoved & 35 & 19 & 0 & $64.8 \%$ & $35.2 \%$ & $0.0 \%$ \\
\hline Scratched & 35 & 19 & 0 & $64.8 \%$ & $35.2 \%$ & $0.0 \%$ \\
\hline Sexually assaulted & 3 & 51 & 0 & $5.6 \%$ & $94.4 \%$ & $0.0 \%$ \\
\hline Shot/shot at & 4 & 50 & 0 & $7.4 \%$ & $92.6 \%$ & $0.0 \%$ \\
\hline Spit on/at & 37 & 17 & 0 & $68.5 \%$ & $31.5 \%$ & $0.0 \%$ \\
\hline Stabbed & 2 & 52 & 0 & $3.7 \%$ & $96.3 \%$ & $0.0 \%$ \\
\hline Sworn/cursed at & 51 & 3 & 0 & $94.4 \%$ & $5.6 \%$ & $0.0 \%$ \\
\hline $\begin{array}{l}\text { Threatened with } \\
\text { physical harm }\end{array}$ & 47 & 7 & 0 & $87.0 \%$ & $13.0 \%$ & $0.0 \%$ \\
\hline Verbally intimidated & 47 & 7 & 0 & $87.0 \%$ & $13.0 \%$ & $0.0 \%$ \\
\hline Voided on/at & 16 & 36 & 2 & $29.6 \%$ & $66.7 \%$ & $3.7 \%$ \\
\hline Yelled/shouted at & 50 & 4 & 0 & $93.0 \%$ & $7.4 \%$ & $0.0 \%$ \\
\hline
\end{tabular}


As is depicted in Table 2, many of the nurses experienced WPV. One hundred percent $(n=54)$ of the participants reported being called names. Non-physical violence such as being sworn at, threatened, and verbally intimated was reported by over $87 \%(n=$ 47) of the sample. Physical violence such as being kicked, pinched, pushed/shoved, and scratched were reported by the majority of the sample. Two nurses $(3.7 \%)$ had experienced being stabbed and four nurses (7.4\%) reported being shot.

Table 3 on the next page illustrates which violent incidents were reported. 
Table 3

Percentage of Participants who Reported the Violent Behaviors

\begin{tabular}{|c|c|c|c|c|c|c|}
\hline \multirow{2}{*}{ Item } & \multicolumn{3}{|c|}{$\begin{array}{l}\text { Response to question } \\
\text { Total } n=54 \text { participants }\end{array}$} & \multirow[b]{2}{*}{$\%$ Yes } & \multirow[b]{2}{*}{$\%$ No } & \multirow{2}{*}{$\begin{array}{c}\% \text { No } \\
\text { Response }\end{array}$} \\
\hline & Yes & No & $\begin{array}{c}\text { No } \\
\text { Response }\end{array}$ & & & \\
\hline Bitten & 5 & 49 & 0 & $9.3 \%$ & $90.8 \%$ & $0 \%$ \\
\hline Called names & 7 & 47 & 0 & $13.0 \%$ & $87.0 \%$ & $0 \%$ \\
\hline Hair pulled & 0 & 52 & 2 & $0 \%$ & $96.2 \%$ & $3.7 \%$ \\
\hline $\begin{array}{l}\text { Harassed with sexual } \\
\text { language/innuendo }\end{array}$ & 7 & 47 & 0 & $13.0 \%$ & $87.0 \%$ & $0 \%$ \\
\hline Hit (e.g., punched, slapped) & 21 & 33 & 4 & $39.0 \%$ & $61.1 \%$ & $7,4 \%$ \\
\hline Hit by thrown objects & 12 & 41 & 1 & $22.2 \%$ & $76.0 \%$ & $1.8 \%$ \\
\hline Kicked & 10 & 44 & 0 & $18.5 \%$ & $81.4 \%$ & $0 \%$ \\
\hline Pinched & 4 & 50 & 0 & $7.4 \%$ & $93.0 \%$ & $0 \%$ \\
\hline Pushed/shoved & 10 & 43 & 1 & $18.5 \%$ & $80.0 \%$ & $1.8 \%$ \\
\hline Scratched & 7 & 47 & 0 & $13.0 \%$ & $87.0 \%$ & $0 \%$ \\
\hline Sexually assaulted & 3 & 51 & 0 & $5.5 \%$ & $94.4 \%$ & $0 \%$ \\
\hline Shot/shot at & 2 & 51 & 1 & $3.7 \%$ & $94.4 \%$ & $0 \%$ \\
\hline Spit on/at & 11 & 43 & 0 & $20.3 \%$ & $79.6 \%$ & $0 \%$ \\
\hline Stabbed & 0 & 54 & 0 & $0 \%$ & $100 \%$ & $0 \%$ \\
\hline Sworn/cursed at & 5 & 48 & 1 & $9.3 \%$ & $88.9 \%$ & $1.8 \%$ \\
\hline Threatened with physical harm & 11 & 43 & 0 & $20.4 \%$ & $79.6 \%$ & $0 \%$ \\
\hline Verbally intimidated & 7 & 47 & 0 & $13.0 \%$ & $87.0 \%$ & $0 \%$ \\
\hline Voided on/at & 0 & 52 & 2 & $0 \%$ & $96.3 \%$ & $3.7 \%$ \\
\hline Yelled/shouted at & 4 & 50 & 0 & $7.4 \%$ & $92.6 \%$ & $0 \%$ \\
\hline
\end{tabular}


The lack of reporting violence is clear from this table. The most frequently reported behavior, that of being hit, was only reported by $39 \%(n=21)$ of the nurses. The behaviors of being kicked, pinched, pushed/shoved, or scratched were reported less than $18.5 \%$ of the time. Non-physical acts such as threatening statements and verbal intimidation were reported less than $20.4 \%$. These figures confirm the lack of reporting of violent incidents.

The top five most commonly experienced acts are depicted in Figure 2 on the following page. There was little difference between males and females with the exception of being threatened with physical harm, which $100 \%$ of the males experienced. It is interesting to note that all of these most commonly experienced acts were non-physical types of behaviors. 


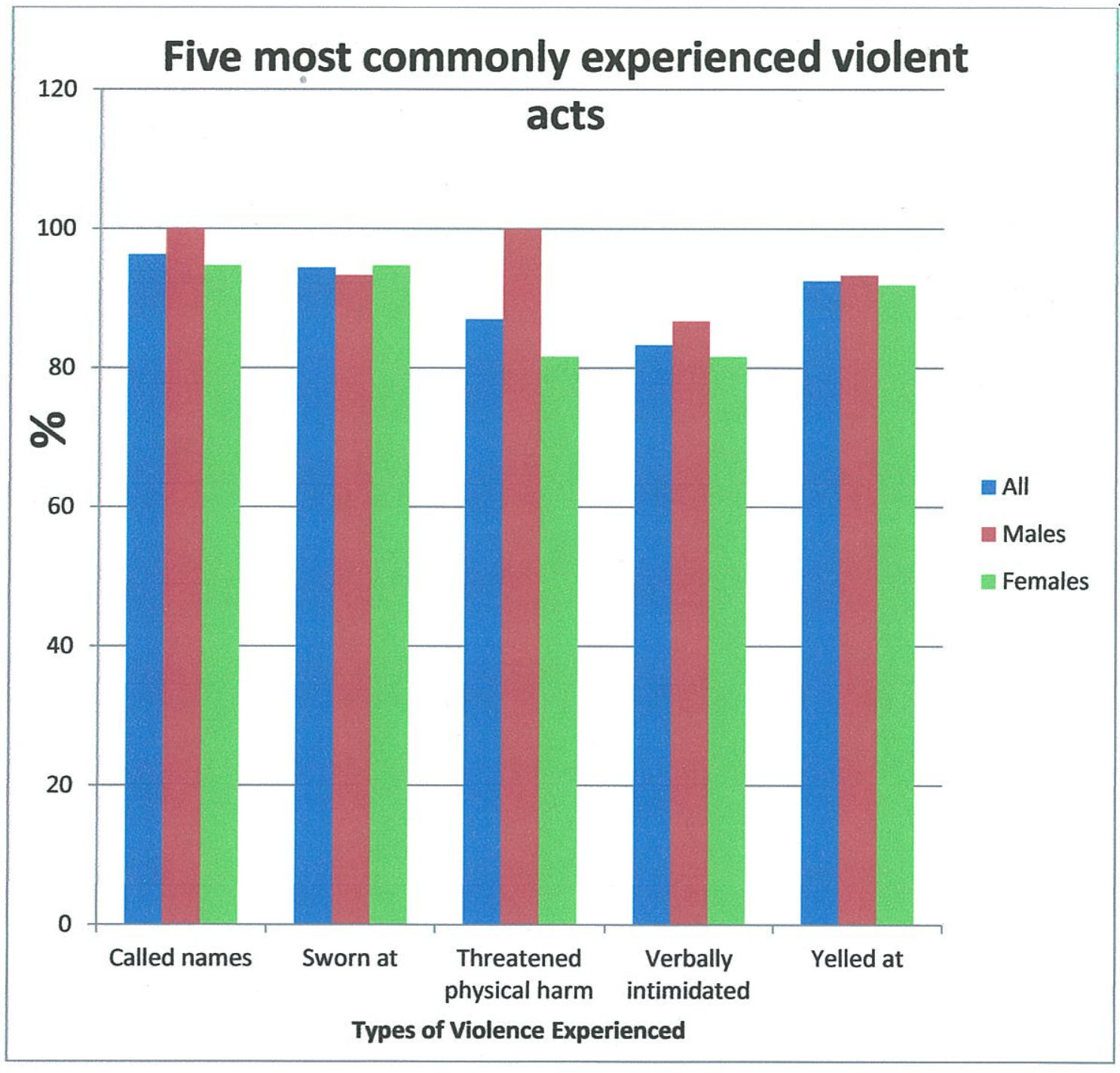

Figure 2. Five most commonly experienced violent acts

Figure 3 on the next page illustrates the five perceived violent behaviors and whether these events were experienced and/or reported. 


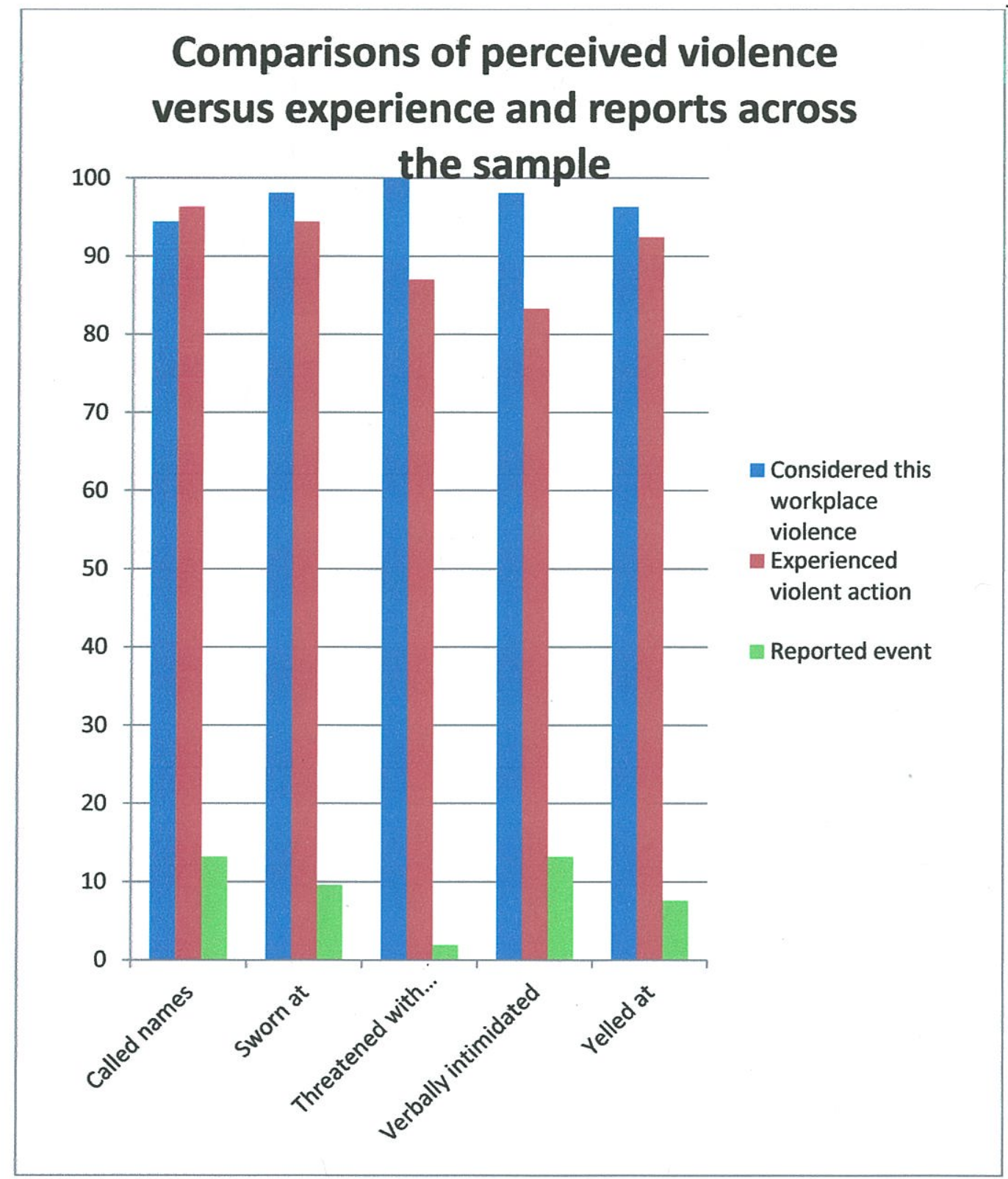

Figure 3. Comparison of perceived violence versus experienced versus reported. 
As this figure clearly illustrates, nurses believed that these acts constituted

violence, they had experienced them, and these incidents were reported less than $13.2 \%$ of the time.

Next, nurses responded to open-ended question that explored the reasons for not reporting violent behaviors. The responses, word repetitions, key words, commonalities, and overlapping statements were analyzed and themes were identified. Since numerous participants reported multiple reasons, there were more responses than sample participants.

Figure 4 on the next page graphically illustrates the five most commonly reported reasons for not reporting.

\section{Reasons for Not Reporting Violent Acts}

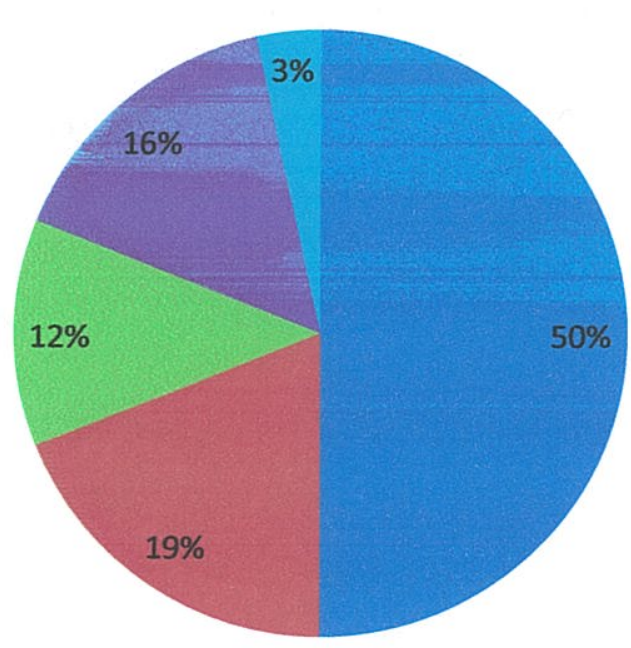

- Nothing will be done by management/hospital or police

- Takes too much time/too busy/too much paperwork

- Patient does not know what they are doing

- Comes with the job/acceptable/happens frequently

- Labeled as a complainer 
Figure 4. Reasons for not reporting violent events.

As is depicted in Figure 4, an overwhelming majority, 50\%, did not report incidents due to the belief that nothing would be done about it. Almost $20 \%$ reported that it takes too much time and/or they were too busy file a report. Fifty- seven percent of participants $(n=31)$ considered WPV as "part of the job". A few nurses $(n=4)$ stated that they didn't think it should be, but that it was. In addition, participants were asked if they felt that violence on the job had increased, remained the same, or increased over the past year. An overwhelming $81.4 \%(n=44)$ reported that violence had increased in the past year. Not a single respondent reported a decrease in violence in the previous year. Summary and conclusions will be discussed next. 


\section{Summary and Conclusions}

Violence in the workplace is a documented and on-going problem for all healthcare professionals, with nurses being especially vulnerable. Psychiatric and emergency settings are considered some of the highest risk areas, with reports of violence ranging from $60 \%$ to $90 \%$ (Lau, Magarey, \& McCutcheon, 2004). Workplace violence (WPV) can be generally defined as emotional, physical, verbal abuse, or threatening and coercive actions in the work setting that causes harm (Anderson, 2002; Gacki-Smith et al., 2009; McPhaul \& Lipscomb, 2004). Nurses who work in the emergency department report the highest number of physical and verbal violent incidents (Gates et al., 2006). Conversely there are multiple studies identifying widespread under-reporting, which could make these figures grossly under-estimated (Chapman \& Styles, 2006; Crilly et al., 2004; Kowalenko et al., 2012).

Nurses are not reporting violent events and this makes it challenging to accurately assess the extent of the problem. The documented reasons for nurses' under-reporting are varied and include lack of physical injury, time consuming paperwork, and the feeling that reporting would not change anything (Gates et al., 2006). Although under-reporting was a theme mentioned frequently in the literature, very few studies were identified that were dedicated specifically to analyzing reporting behaviors. Violence in the workplace has negative effects and ultimately threatens the effective and safe patient care (ICN, 2006). Additionally, nurses suffer from psychological as well as physical impacts and 
that can directly contribute to higher attrition rates and escalation of health care costs (Lau et al., 2004). The overall impact of this issue cannot be overstated.

The purpose of the study was to explore if nurses were under reporting violent events in the emergency department and what the factors were contributing to this behavior. In order to accomplish this, an anonymous survey was utilized that was adapted from the ENA 2007 workplace violence survey. The survey was made available to $177 \mathrm{RNs}$ working in the ED for a period of three weeks. IRB approved flyers and emails were distributed and announcements were made at the start of several shifts by this researcher to publicize the survey.

Participants were asked to complete a survey that included a 19 item checklist of behaviors that could constitute WPV. Respondents were asked to indicate if they considered each act to be WPV, whether they had experienced it, and whether they had reported the behavior. A total of 54 surveys were completed, which constituted $30.3 \%$ response rate. The sample included a gender distribution of $29.4 \%$ males $(n=15)$ and 70 , $3 \%$ females $(n=38)$. Most of the participants had more than 10 years of nursing experience.

Overall most participants considered all the behaviors to be WPV. Surprisingly, five nurses did not consider being shot WPV. The validity of this response must be considered. The five most frequently reported events were non-physical in nature and consisted of being called names; being sworn at; being threatened with physical harm; 
verbal intimidation; and being yelled at. It is remarkable that over $80 \%$ of the

respondents considered these to be WPV as well as experiencing these behaviors and yet reported it less than $13.2 \%$ of the time. This data supports what has been found in the literature, that under-reporting is occurring.

Three open-ended questions were included with this survey. When asked if they thought that WPV was "part of the job", over half of the respondents answered affirmatively. Several nurses added comments that although they considered it part of the job, it shouldn't be. In response to the question of whether nurses believed violence had increased, stayed the same, or decreased in the past year, not a single participant reported a decrease. The reasons or "barriers" to reporting WPV revealed remarkably that $50 \%$ of the sample felt that nothing would be done if they reported the violent event. Another $20 \%$ thought that it took too much time and that they were too busy to file a report. Other barriers included statements that: the patients don't know what they are doing related to psychiatric or substances abuse issues; some of these behaviors are to be expected and come with the job; or that they would labeled as a complainer for reporting.

There were several limitations to this study. The survey was based on self-report so the data that was collected can be inaccurate if they nurses did not recall specifics or were not truthful. Because a convenience sampling method was used at one hospital ED, the results are not generalizable to the broader population. The survey was only available for a three week period which may have contributed to the $30 \%$ response rate. The 
demographic data collected was limited to years of experience, shift worked, and sex. More detailed information regarding educational background, age, or ethnicity might have served to evaluate the results more thoroughly and determine if findings were impacted by additional factors.

Based on the findings from this study, it can be concluded that nurses in this ED are experiencing WPV and are under- reporting it. This is consistent with findings from multiple studies highlighted in the literature review. The overwhelming reason cited by $50 \%$ of the participants for not reporting WPV was the feeling that no one cares and nothing will be done about it. The nurses reported that neither, management, police, nor administration would do anything if they reported incidents. In addition, $20 \%$ felt that the paper work and time involved in reporting an incident was too difficult and/or time consuming.

Next, recommendations and implications will be discussed. 


\section{Recommendations and Implications}

A recommendation for this ED based on the results of this study would be to implement a mandatory WPV reporting policy. Nurses are not reporting for various reasons including most importantly the belief that management will not do anything about it. This under-reporting behavior can directly contribute to the lack of response by management if the scope of the problem is not fully appreciated. If the nurses are not reporting WPV, management might believe it is not a serious problem and not consider it a priority. In order to address this grave issue, an accurate assessment of the scope of the problem must be accomplished. The first step to realizing this goal is to eliminate the barriers described by the nurses. Procedures and policies need to be established for reporting WPV and communicated to all nursing staff. Management needs to convey their commitment to a safe working environment and encourage documentation of violence in any form. Nursing leaders at every level, from clinical managers to nursing executives, need to embrace the seriousness of this issue and the ramifications of WPV against nursing personnel. A culture of acceptance for documenting WPV and mandatory follow-up by management after every incident should be instituted.

This research project has clearly established that nurses in this ED are experiencing WPV and rarely reporting it. The limitations of this study described earlier make it difficult to make large generalizations but the findings are significant for this ED and require further assessment. The data suggests that an overwhelming majority do not 
report WPV because nothing will be done about it. The enormity of this issue needs to be addressed in a timely manner. The advanced practice nurse could be instrumental in spearheading a committee to establish policies, procedures, and guidelines for eliminating barriers to reporting WPV and instituting mandatory reporting. The committee should consist of ED RNs, all levels of management and administration (nursing and medical), security, and the local police. The APRN has the education and training to be an excellent collaborator in this situation. The APRN also has the knowledge and skills required to design a larger scale research survey to validate the findings of this project. The findings could serve as the foundation for establishing new policies regarding WPV reporting and ultimately mitigation.

The education of staff nurses regarding the negative impact and sequelae of continuing violence should be a priority. The APRN has the knowledge to disseminate evidence based findings about violence against nurses and the utmost importance of reporting and documenting all incidents. This education could be accomplished in several ways: through staff meetings, power point presentations, posters, and informational brochures are just a few examples. In addition, management and administration need to be made aware of the enormity of this issue and the grave consequences it is causing to staff and ultimately, patient safety. This informational training includes not only nursing but all members of the healthcare team to include physicians, residents, and ancillary 
staff. The APRN can fulfill the role of educator, change agent and expert for this crucial matter.

The findings of this survey highlight several additional topics where future research could be beneficial. As mentioned earlier in this work, this survey could be repeated on a larger scale and at other local hospital emergency departments in this area. If the findings of this study are validated they could prove to be instrumental in highlighting the seriousness of this problem. A qualitative study examining the knowledge and beliefs of hospital management/ administration regarding WPV could be undertaken to establish some baseline data concerning the seemingly lack of concern or response to violent incidents.

Violence in healthcare is global problem. Nurses are particularly vulnerable and are most often the targets. In order to mitigate this violence hospital administrators as well as society as a whole need to be made aware of just how pervasive WPV is. There are several states that have specific laws protecting nurses from assault but they are the minority. Stricter laws on state and federal levels need to be made a priority. The APRN can help affect this change by participating as a leader and member of nursing organizations and taking an active role in the education of the public and our legislative leaders as well as through evidence based research. Calculating the nature and extent of this problem starts with the basic act of reporting it. Under-reporting continues to be widespread and actions need to be taken to eliminate the barriers to reporting and 
obtaining an accurate and true assessment of this extremely serious issue that nurses

are continuing to experience. 


\section{References}

Ajzen, I. (1991). The theory of planned behavior. Organizational Behavior and Human Decisions Processes, 50, 179-211.

Ajzen, I. (2006). TPB Diagram. Retrieved from http://people.umass.edu/aizen/tpb.diag.html

Ajzen, I. (2011). The theory of planned behavior: reactions and reflections. Psychology and Health, 26(9), 1113-1127.

Ajzen, I. (2012). The theory of planned behavior. In Handbook of theories of social psychology, pp. 439-459). London, UK: Sage.

Anderson, C. (2002, June 1). Workplace violence: are some nurses more vulnerable? Issues in Mental health Nursing, 23, 351-366.

http://dx.doi.org/10.1080/01612840290052569

Cameron, R., Ginsburg, H., Westhoff, M., \& Mendez, R. V. (2011, March 1). Ajzen's theory of planned behavior and social media use by college students. American Journal Of Psychological Research, 8(1), 1-20.

Campbell, J. C., Messing, J. T., Kub, J., Agnew, J., Fitzgerald, S., Fowler, B., ... Bolyard, R. (2011). Workplace violence prevalence and risk factors in the safe at work study. Journal of Occupational and Environmental Medicine, 53, 82-87.

Canadian Centre for Occupational Health and Safety (CCOHS). (2012). Violence in the workplace. Retrieved from http:/www.ccohs.ca/keytopics/wplace_violence.html 
Catlette, M. (2005). A descriptive study of the perceptions of workplace violence and safety strategies of nurses working in level I trauma centers. Journal of Emergency Nursing, 31(6), 519-525.

Chapman, R., \& Styles, I. (2006). An epidemic of abuse and violence: nurse on the front line. Accident and Emergency Nursing, 14, 245-249. http://dx.doi.org/10.1016/j.aaen.2006.08.004

Crilly, J., Chaboyers, W., \& Creedy, D. (2004). Violence towards emergency department nurses by patients. Accident and Emergency Nursing, 12, 67-73.

Danesh, V. C., Malvey, D., \& Fottler, M. (2008). Hidden workplace violence what your nurses may not be telling you. The Health Care Manager, 27, 357-363.

DiMartino, V. (2002). Workplace violence in the health sector: A synthesis report. Retrieved from: http://www.who.int/violence_injury_prevention/injury/en/WVsynthesisreport.pdf Dykstra, L. (2011). [Violence Risk Self-Assessment Checklist]. Unpublished raw data. Dykstra, L. (2013). [Violence Risk]. Unpublished raw data. Emergency Nurse Association. 2010. ENA workplace violence toolkit. Retrieved from: www.ena.org/practice-research/practice/violencetoolkit/document/toolkitpg4.htm

Ferns, T., \& Diphe, B. (2005). Violence in the accident and emergency department - an international perspective. Accident and Emergency, 13, 180-185. http://dx.doi.org/10.1016/j.aaen.2005.03.005 
Gacki-Smith, J., Juarez, A. M., Boyett, L., Homeyer, C., Robinson, L., \& Maclean, S.

L. (2009). Violence against nurses working in US emergency departments. The Journal of Nursing Administration, 39, 340-349.

Gates, D. M., Ross, C. S., \& McQueen, L. (2006). Violence against emergency department workers. The Journal of Emergency Medicine, 31, 331-336.

Greene, P. K. (2009). Workplace violence: prevention \& early intervention. Health Careers Today, 16-23. Retrieved from http://www2.mysanantonio.com/client_pdfs/hct0509p16-23uhsviolence.pdf

Hader, R. (2008). Workplace violence survey 2008:unsettling findings. Nursing Management, 39(7), 13-17.

International Council of Nurses. Abuse and violence against nursing personnel. (2006). Retrieved from www.icn.ch

Keely, B. R. (2002). Recognition and prevention of hospital violence. Dimensions of Critical Care Nursing, 21, 236-241.

Kowalenko, T., Cunningham, R., Sachs, C. J., Gore, R., Barata, I. A., Gates, D., ... McClain, A. (2012). Workplace violence in emergency medicine: current knowledge and future directions. The Journal of Emergency Medicine, 43, 523531. http://dx.doi.org/10.1016/j/jemermed.2012.02.056

Lau, J. B., Magarey, J., \& McCutcheon, H. (2004). Violence in the emergency department a literature review. Australian Emergency Nursing Journal, 7, 27-37. 
Lundrigan, E., Hutchings, D., Matthews, M., Lynch, A., \& Goosney, J. (2010). A risk assessment screening tool for community healthcare workers. Home Healthcare Management and Practice, 22, 403-407.

McEwen, M., \& Wills, E. M. (2011). Theoretical basis for nursing (3rd ed.). Philadelphia, PA: Lippincott, Williams \& Wilkins.

McPhaul, K. M., \& Lipscomb, J. A. (2004). Workplace violence in health care: recognized but not regulated. The Online Journal of Issues in Nursing, 9. Retrieved from http://www.nursingworld.org/ojin/

Merchant, J., \& Lundell, J. (Eds.). (2001). Proceedings from the University of Iowa Injury Prevention Research Center Workshop: Workplace Violence: A Report to the Nation. Iowa City, IA: University of Iowa.

National Institute for Occupational Safety and Health (NIOSH). (2002). Workplace Violence [Fact Sheet]. Retrieved from Occupational Safety and health Administration: www.cdc.gov/niosh/

Occupational Safety and Health Administration (OSHA). (2012). Workplace violence. Retrieved from https://osha.gov/SLTC/healthcarefacilities/violence.html

Speroni, K., Fitch, T., Dawson, E., Dugan, L., \& Atherton, M. (2014). Incidence and cost of nurse workplace violence perpetrated by hospital patients or patient visitors. Journal of Emergency Nursing 2014 40(3), 218-28. 
Stokowski, L. A. (2010). Violence: Not in my job description. Retrieved from www.medscape.com/viewarticle/727144_print

Strickler, J. (2013). When it hurts to care: workplace violence. Nursing 2013, 43(4), 5962.

Wolf, L., Delao, A., \& Perhats, C. (2014). Nothing changes, nobody cares: understanding the experience of emergency nurses physically or verbally assaulted while providing care. Journal of Emergency Nursing, 40, 305-309. 


\section{Appendix A}

Gender

Shift primarily worked

Years of experience

$\begin{array}{llll}\text { Male } \square & \text { Female } \square & \\ \text { Days } \square & \text { Evenings } & \square & \text { Nights } \square \\ 0-10 \square & 10-20 & \square & \text { Over 20 } \square\end{array}$

From the actions listed below, indicate which of the following items you believe to constitute workplace violence. Additionally, indicate whether you have personally experienced any of the items.

\begin{tabular}{|c|c|c|c|c|c|c|}
\hline & $\begin{array}{r}\text { I cor } \\
\text { act } \\
\text { workp! }\end{array}$ & $\begin{array}{l}\text { this } \\
\text { be } \\
\text { olence }\end{array}$ & $\begin{array}{l}\text { I have } \\
\text { experien } \\
\text { while at }\end{array}$ & $\begin{array}{l}\text { ally } \\
\text { action } \\
\text { his ED }\end{array}$ & $\begin{array}{r}\text { Did y } \\
\text { thi }\end{array}$ & $\begin{array}{l}\text { port } \\
\text { nt }\end{array}$ \\
\hline & Yes & No & Yes & No & Yes & No \\
\hline Bitten & $\square$ & $\square$ & $\square$ & $\square$ & $\square$ & $\square$ \\
\hline Called names & $\square$ & $\square$ & $\square$ & $\square$ & $\square$ & $\square$ \\
\hline Hair pulled & $\square$ & $\square$ & $\square$ & $\square$ & $\square$ & $\square$ \\
\hline $\begin{array}{l}\text { Harassed with sexual } \\
\text { language/innuendo }\end{array}$ & $\square$ & $\square$ & $\square$ & $\square$ & $\square$ & $\square$ \\
\hline $\begin{array}{l}\text { Hit (e.g., punched, } \\
\text { slapped) }\end{array}$ & $\square$ & $\square$ & $\square$ & $\square$ & $\square$ & $\square$ \\
\hline Hit by thrown objects & $\square$ & $\square$ & $\square$ & $\square$ & $\square$ & $\square$ \\
\hline Kicked & $\square$ & $\square$ & $\square$ & $\square$ & $\square$ & $\square$ \\
\hline Pinched & $\square$ & $\square$ & $\square$ & $\square$ & $\square$ & $\square$ \\
\hline Pushed/shoved & $\square$ & $\square$ & $\square$ & $\square$ & $\square$ & $\square$ \\
\hline Scratched & $\square$ & $\square$ & $\square$ & $\square$ & $\square$ & $\square$ \\
\hline Sexually assaulted & $\square$ & $\square$ & $\square$ & $\square$ & $\square$ & $\square$ \\
\hline Shot/shot at & $\square$ & $\square$ & $\square$ & $\square$ & $\square$ & $\square$ \\
\hline Spit on/at & $\square$ & $\square$ & $\square$ & $\square$ & $\square$ & $\square$ \\
\hline Stabbed & $\square$ & $\square$ & $\square$ & $\square$ & $\square$ & $\square$ \\
\hline Sworn/cursed at & $\square$ & $\square$ & $\square$ & $\square$ & $\square$ & $\square$ \\
\hline $\begin{array}{l}\text { Threatened with } \\
\text { physical harm }\end{array}$ & $\square$ & $\square$ & $\square$ & $\square$ & $\square$ & $\square$ \\
\hline
\end{tabular}




\begin{tabular}{|l|c|c|c|c|c|c|}
\hline Verbally intimidated & $\square$ & $\square$ & $\square$ & $\square$ & $\square$ & $\square$ \\
\hline Voided on/at & $\square$ & $\square$ & $\square$ & $\square$ & $\square$ & $\square$ \\
\hline Yelled/shouted at & $\square$ & $\square$ & $\square$ & $\square$ & $\square$ & $\square$ \\
\hline Other (describe): & $\square$ & $\square$ & $\square$ & $\square$ & $\square$ & $\square$ \\
\hline Other (describe): & $\square$ & $\square$ & $\square$ & $\square$ & $\square$ & $\square$ \\
\hline Other (describe): & $\square$ & $\square$ & $\square$ & $\square$ & $\square$ & $\square$ \\
\hline
\end{tabular}

If you did not report the described behaviors what was the reason for not reporting the behaviors?

Do you feel workplace violence from patients and/or visitors is simply "part of the job" in the ED?

Yes

No

Do you feel workplace violence has increased, remained the same or decreased over the past year?

Increased

Remained the same

Decreased

(Modified from ENA Workplace Violence Survey 2009 toolkit for violence) 